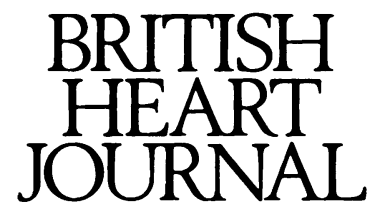

Editorial

\title{
Research on coronary disease in women: political or scientific imperative?
}

Research in coronary disease and other health issues in women is receiving increasing emphasis in the United States. Legislators have questioned whether women and women's health are adequately represented in federally supported studies. ${ }^{1}$ The National Institutes of Health (NIH) has recently strengthened its policies of including women and minorities in every clinical research study it funds. ${ }^{2}$ The NIH director, Dr Bernadine Healy, has proposed an NIH-wide initiative for an extensive study of the effects of diet, hormone replacement, and calcium supplementation on the major causes of death and disability in women, ${ }^{3}$ and studies targeted specifically at coronary disease in women are being undertaken by the National Heart, Lung, and Blood Institute (NHLBI) of the NIH.

This increased attention has raised questions about the motivation and wisdom of such efforts. ${ }^{4}$ At times it may be unclear whether they are driven by politics or science. Have women really been neglected in cardiovascular research? Are women so different from men in regard to coronary disease that information obtained from men is not generalisable to them? Given their lower rates of coronary disease, is coronary disease even an important problem in women? As scientists and administrators at the NHLBI and the NIH, we have enjoyed a unique perspective on these issues in the past several years.

\section{Status of research on women}

Undeniably, women have been under-represented in large-scale randomised clinical trials of coronary disease prevention. In population-based observational studies, however, they have often been equally or even over-represented; the Framingham Heart Study cohort, for instance, was initially $51 \%$ female and is currently $60 \%$ female. Past intervention studies focused on men for various reasons, not the least of which was that their higher event rate led to greater study power and efficiency. Additionally, there was a focus on premature coronary disease, to which women are far less susceptible than men. A recent review of studies on cholesterol and coronary disease risk included far fewer studies of women than men and showed only a modestly $(12 \%)$ increased risk associated with raised cholesterol in older women. ${ }^{5}$ Recognising that many studies have been conducted primarily or exclusively in middle aged men, does it necessarily follow that more research is needed in women?

\section{Sex differences in coronary disease}

Substantial sex differences in presentation, course, and treatment of coronary disease raise significant concerns regarding the generalisability of data from men to women. Heart disease in women becomes clinically evident about 10 years later than in men ${ }^{6}$ and is more likely to present as angina. ${ }^{7}$ Incidence of myocardial infarction in women lags behind that of men by almost 20 years, and when myocardial infarction occurs it is more likely to be unrecognised in women. Though sudden death is a less frequent presentation of coronary disease in women than in men, initial episodes of coronary disease are more likely to be fatal in women. ${ }^{6}$ The clinical course of myocardial infarction in women is considerably less favourable than in men. Relative risks of death, recurrent infarction, and stroke are all greater in women than in men after an initial infarction. ${ }^{6}$ Perioperative mortality after coronary bypass grafting is twice that of men, ${ }^{8}$ despite documented higher ejection fractions after infarction in women. ${ }^{9}$ Poorer outcome after coronary bypass in women may be explained by smaller coronary artery size, ${ }^{1011}$ but available data are inconsistent. ${ }^{12}$ Lower success rates of percutaneous transluminal coronary angioplasty (PTCA) have been reported in women but do not seem to be explained bydifferences in age or body size. ${ }^{13}$

In the United States treatment of coronary disease also differs considerably for women, particularly in regard to referral for angiography and revascularisation. In one recent study, women with myocardial infarction were only half as likely to have undergone coronary angiography or bypass surgery as were men, even after adjustment for age and coexisting illness. ${ }^{14}$ The question whether sex differences in rates of revascularisation procedures represent under-utilisation of these interventions in women or overutilisation in men has engendered some debate. ${ }^{15}$ Recent data suggest that women with more symptomatic and severe disease, in whom coronary bypass offers the greatest survival benefits, were at least as likely as men to be referred for such surgery. ${ }^{16}$ The male predominance pertained only to patients at low risk for cardiac death, in whom coronary bypass offers little or no survival benefit, suggesting that intervention decisions were being made more appropriately in women.

Irrespective of the appropriateness of decision making, it is clear that decisions are made differently for women than for men even after adjusting for factors believed most likely to influence outcome. Reasons for such differences remain obscure, and as well as being of scientific interest they also have important implications for health care policy.

One major difference in non-surgical treatment options between men and women is the use of hormone replacement therapy after menopause. Whereas high-dose oestrogen therapy ( $5 \mathrm{mg}$ conjugated equine oestrogens daily) 
in men with coronary disease was shown to increase mortality, ${ }^{17}$ epidemiological studies have demonstrated substantially lower cardiovascular mortality in postmenopausal women taking replacement oestrogens. ${ }^{18}$ The risk of endometrial cancer and potential risks of breast cancer associated with oestrogen therapy are likely to be greatly outweighed by the improved survival from cardiovascular disease, which kills far more women than do hormone-related cancers. Clinical trials to assess the effects of hormone replacement on progression of coronary atherosclerosis and prevention of overt coronary disease are being planned and will directly address the benefits and risks of oestrogen therapy on multiple outcomes in postmenopausal women. Similar clinical trials of tamoxifen, an oestrogen agonist-antagonist, are currently underway.

\section{Importance of coronary disease in women}

Although gender differences in coronary disease prevalence and mortality persist throughout the lifespan, they narrow considerably above age 65.1920 The considerable decline in coronary mortality in the past quarter century is clearly a desirable trend, but it has left in its wake an increasing number of coronary survivors at increased risk for disability and recurrent disease, particularly in older ages. Prevalent coronary disease is also a strong determinant of disability in older adults, particularly among women; approximately half of women with heart disease report limitations in their activity as a result of their disease. ${ }^{19}$ In addition, as age increases beyond 65 years, so does the proportion of the population that is female. Above age 65 years, when more than four fifths of all coronary disease deaths occur, more women than men die of coronary disease; above age $\mathbf{8 5}$ more than twice as many women as men die of coronary disease simply because there are so many more of them. Given the great increases in the United States population over age 65 in the past three decades, and the even greater increases expected in the next century as the "baby boom" generation ages, the United States faces a near tidal wave of coronary disease in the elderly, most of whom are women. While the economic implications of this shift are enormous, the political implications are even greater, since the medical care of persons over age 65 is supported almost entirely by the federally funded Medicare program.

\section{Politics or science?}

Coronary disease research in women is thus both a political and a scientific imperative. The policy implications of a substantial increase in the number of elderly women requiring medical care for coronary disease are undeniable, but if policy is dictating the urgency with which these needs are met, science must continue to set the agenda for research. Based on the available information, one can formulate a number of scientific questions unique to women which can only be addressed by research directed at them. Why do coronary risk factors seem to differ in men and women? Why is the clinical course of coronary disease in women often so much more severe than that of men, after controlling for age, extent of disease, and coexisting illness? How can the considerable sex differences in treatment in the United States be explained and, if necessary, corrected? What are the risks and benefits of hormone replacement therapy in primary and secondary prevention in women?
Coronary disease is the leading cause of death and a major cause of morbidity and disability in women and will continue to increase in importance in an aging population. Its social and economic impact, as well as the toll it takes in suffering and death among women, cannot be ignored. If such considerations are translated into health care policy, then they inevitably become "political"; but properly so in the sense of the Greek politikos, "citizen", as addressing a health care issue affecting the majority of United States citizens, rather than in the more sinister sense of "... competition between competing interest groups or individuals for power and leadership". ${ }^{21}$ But as these political imperatives cannot be ignored, neither can we disregard the scientific opportunities presented by studying a large segment of coronary disease patients with courses different from the vast majority of patients studied and reported upon to date. Such opportunities do not often present themselves in science. Recognising and capitalising on them are scientific imperatives that must not be denied.

Division of Epidemiology and

TERI A MANOLIO

Clinical Applications, National Heart,

Lung, and Blood Institute,

Bethesda, MD 20892, USA.

WILLIAM R HARLAN

Office of Disease Prevention,

National Institutes of Health,

Bethesda, MD 20892, USA.

1 Healy B. Women's health, public welfare. $\mathcal{F A M A}$ 1991;266:566-8.

2 Pinn VW. Commentary: Women, research and the National Institutes of Health. Am F Prev Med 1992;8:324-7.

3 Healy B. The Yentl syndrome. Engl F Med 1991;325:274-5.

4 Blackburn H. Ancel Keys Lecture. Circulation (in press).

5 Manolio TA, Pearson TA, Wenger NK, Barrett-Connor E, Payne GH Harlan WR. Cholesterol and heart disease in older persons and women: overview of an NHLBI workshop. Ann Epidemiol 1992; 2:161-76.

6. Kannel WB, Abbott RD. Incidence and prognosis of myocardial infarction in women: The Framingham Study. In: Eaker ED, Packard B, tion in women: The Framingham Study. In: Eaker ED, Packard B, Wenger NK, Clarkson TB, Tyroler HA, eds. Coronary

7 Beard CM, Foster V, Annegers JF. Reproductive history in women with coronary heart disease: A case-control study. Am $\mathcal{f}$ Epidemiol 1984;120:108-14.

8 Wenger NK, Roberts R. Clinical aspects of coronary heart disease in women. In: Eaker ED, Packard B, Wenger NK, Clarkson TB, Tyroler HA, eds. Coronary heart disease in women. New York: Haymarke Doyma, 1987; 22-8.

9 Tofler GH, Stone JH, Muller JE, et al. Effects of gender and race on prognosis after myocardial infarction: adverse prognosis for women, particularly black women. $\mathcal{f} \mathrm{Am}$ Coll Cardiol 1987;9:473-82.

10 Fisher LD, Kennedy JW, Davis KB, et al. Association of sex, physical size, and operative mortality after coronary artery bypass in the Coronary Artery Surgery Study (CASS). Thorac Cardiovasc Surg 1982, 84:334-41.

11 Loop FD, Golding LR, Macmillan JP, et al. Coronary artery surgery in women compared with men: Analyses of risks and long-term results. J Am Coll Cardiol 1983;1:383-90.

12 Khan SS, Nessim S, Gray R, Caer LS, Chaux A, Marloff J. Increased mortality of women in coronary artery bypass surgery: evidence for mortality of women in coronary artery bypas
referral bias. Ann Intern Med 1990;112:561-7.

13 Cowley MJ, Mullin SM, Kelsey SF, et al. Sex differences in early and long-term results of coronary angioplasty in the NHLBI PTCA long-term results of coronary
Registry. Circulation 1985;71:90-7.

14 Steingart RM, Packer $M$, Hamm $P$, et al. Sex differences in the manageteingart RM, Packer M, Hamm P, et al. Sex differences in the $m$,
ment of coronary artery disease. N Engl f Med 1991;325:226-30.

15 Ayanian JZ, Epstein AM. Differences in the use of procedures between women and men hospitalized for coronary heart disease. $N$ Engl $\mathcal{F}$ Med 1991;325:221-5

16 Bickell NA, Pieper KS, Lee KL, Mark DB, Glower DD, Pryor DB, Califf RM. Referral patterns for coronary artery disease treatment: Gender bias or good clinical judgment? Ann Intern Med 1992;116:791-7.

17 Coronary Drug Project Research Group. The Coronary Drug Project: Initial findings leading to modifications of its research protocol. $\mathfrak{f} A M A$ 1970;214:1303-13.

18 Bush TL, Barrett-Connor E. Noncontraceptive oestrogen use and cardiovascular disease. Epidemiol Rev 1985;71:80-104.

19 Adams PF, Benson V. Current estimates from the National Health Statistics. Vital Health Stat 1991;10(181):85.

20 National Center for Health Statistics. Vital statistics of the United States, 1989. Vol. II. Mortality, Part A. Public Health Service, Washington: 1989. Vol. Il. Mortality, Part A. Public

21 Mish FC, ed. Webster's ninth new collegiate dictionary. Springfield MA Merriam-Webster, 1984;911. 